\title{
KHẢO SÁT HÌNH THÁI MŨI NGOÀI TRÊN BÊNH NHÂN VẸO VÁCH NGĂN TẠI BỆNH VIỆN CHỢ RẪY
}

\section{TÓM TẮT}

Mục tiêu: Khảo sát hình thái mũi ngoài trên bệnh nhân vẹo vách ngăn tại Bệnh viện Chợ Rẫy từ tháng 9/ 2019 đến 9/ 2020. Phương pháp nghiên cứu: báo cáo hàng loạt ca. Trong thời gian 9/2019 đến 9/ 2020 khảo sát 250 trường hợp. Vẹo vách ngăn được đánh giá qua nội soi và khám lâm sàng, vẹo mũi ngoài được đánh giá qua các mốc giải phẫu trển chụp hình độ phân giải cao. Kết quá: Vẹo tháp mũi chiếm $19,2 \%$ trường hợp với vẹo tháp mũi loại $\mathrm{V}$ là hay gặp nhất $(5,6 \%)$, sau đó là loại III $(5,2 \%)$, loại IV $(4,4 \%)$, loại I $(2,4 \%)$, loại II $(1,6 \%)$. Nam giới hay gặp veo tháp mũi loại $\mathrm{V}$, nữ giới hay gặp vẹo tháp mũi loại IIII. Kết luân: Veo mũi ngoài có mối liên quan với vẹo vách ngăn đặc biệt, vẹo vách ngăn loại 2 hay gặp ở veo tháp mũi xương và tháp mũi sụn cùng hướng. Vẹo vách ngăn loại 4 hay gặp ở tháp mũi xương vẹo kết hợp với vẹo tháp mũi sụn nhưng ngược hướng. Vẹo vách ngăn loại 7 hay gặp ở vẹo tháp mũi sự đơn thuân.

Tư khóa: vẹo tháp mũi, vẹo vách ngăn, vẹo tháp mũi xương, vẹo phần van mũi, vẹo tháp mũi sụn

\section{SUMMARY}

\section{SURVEY OF EXTERNAL NASAL}

\section{DEFORMITIES IN NASAL SEPTAL}

DEVIATION AT CHO RAY HOSPITAL

Objective: to investigate the external nasal deformities in nasal septal deviation at Cho Ray hospital from 9/ 2019 to 9/ 2020. Methods: case series report. There arc 250 cases from September, 2019 to September, 2020. Nasal sepal deviations is evaluated by clinical examination and diagnostic nasal endoscopy while external nasal deformities was evaluated some anatomical markers by high resolution photography. Results: Therc arc 48/ 250 (19,2\%) cases external nasal deformities in nasal septal deviations. In those patents with external nasal deformities, type $\mathrm{V}(5,6 \%)$ was the most commonly observed external deformity. Following deformities consist of type II $(5,2 \%)$, tyoe IV $(4,4 \%)$, type I $(2,4 \%)$, type II $(1,6 \%)$. Type $V$ was seen more common in male and type III was shown more common in female.Conclusions: External nasal deformities have correlative with special nasal septal deviations. Type 2 nasal septum deviations was seen more common in deviated bone pyramid and cartilage pyramid deviation same direction. Type 4 nasal septum deviations was seen more common in deviated bone pyramid and cartilage pyramid

\section{*Bệnh viện Chợ Rẫy}

Chịu trách nhiệm chính: Ngô Văn Công

Email: congtmh@gmail.com

Ngày nhận bài: 16.3.2021

Ngày phản biện khoa học: 14.5.2021

Ngày duyệt bài: 19.5.2021
Ngô Văn Công*

deviation opposited direction. Type 7 nasal septum deviations was shown more common in simple cartilage pyramid deviation.

Keywords; deviated nasal pyramid, deviated nasal septum, external nasal deformities, bone pyramid deviation, deviated nasal vale part.

\section{I. ĐẶT VẤN ĐỀ}

Mũi nằm ở trung tâm vùng mặt nên hình dáng của mũi ngoài góp phần tạo nển tính thẩm mỹ của khuôn mặt. Khi mũi hài hòa sẽ tạo nên đường nét thanh tao, ngược lại khi mũi ngoài bị biến dạng (gồ, vẹo), khuồn mặt mất đi vẻ hấp dẫn. Do đó, bất cứ bất thường về hình dạng của mũi ngoài đều gây ảnh hưởng đến thẩm mỹ khuôn mặt. Nguyên nhân dị dạng mũi ngoài bao gồm các khiếm khuyết phần khung mũi xương, khung mũi sụn, dị dạng vách ngăn hoặc phối hợp các yếu tố trên [4], [8]. Tác giả Godley [5] đều cho rằng các trường hợp vẹo mũi nặng có liên quan đến sự xuất hiện của dị dạng vách ngăn. Do đó bất thường ở hình dạng vách ngăn có thể ảnh hưởng trực tiếp đến thẩm mỹ của mũi ngoài. Sự biểu hiện giữa vẹo vách ngăn và hình thái mũi ngoài chưa có nhiều nghiên cứu khảo sát. Do đó, để hiểu rõ hơn mối tương quan này, tôi tiến hành: "Khảo sát hình thái mũi ngoài trên bệnh nhân vẹo vách ngăn tại bệnh viện Chợ Rẫy từ tháng 9/2019 đến tháng 9/2020".

\section{II. ĐỐl TƯỢNG VÀ PHƯƠNG PHÁP NGHIÊN CỨU}

Tiêu chuẩn chọn mẫu. Bệnh nhân đủ 18 tuổi, tham gia nghiển cứu là những bệnh nhân được chẩn đoán vẹo vách ngăn qua khám lâm sàng và nội soi.

Tiêu chuẩn loại trừ: Bệnh nhân có tổn thương u vùng mặt và hốc mũi; bệnh nhân bị liệt mặt, sẹo cũ vùng mặt có ảnh hưởng đến hình dạng mũi ngoài, khuôn mặt VA; bệnh nhân có tiền sử chấn thương hàm mặt, mũi, vách ngăn được ghi nhận; bệnh nhân đã được phẫu thuật chỉnh hình vách ngăn, chỉnh hình mũi; bệnh nhân không đồng ý tham gia nghiên cứu.

Phương pháp nghiên cứu: mô tả hàng loạt ca

Phương pháp tiến hành:

Bước 1: Chụp hình đối tượng nghiên cứu theo 2 tư thế: mặt thẳng, mặt nghiêng 90 độ. Dùng viết lông đầu nhỏ chấm các điểm nhỏ trền mă̆t để xác định các điểm mốc giải phẫu (1. Điểm trên gốc mũi $(\mathrm{gl})$, 2. Điểm gốc mũi $(\mathrm{n}), 3$. Điểm khớp xương sụn $\AA^{\circledR}$, 4. Điểm chóp mũi $(\mathrm{t})$, 
5. Điểm dưới mũi (sn), 6. Điểm môi trên (Is))

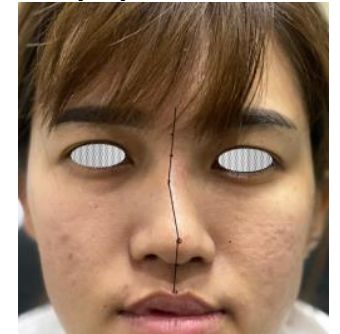

Mặt thẳng

Bước 2: Dựa trên ảnh tư thế mặt thẳng: Xác định đoạn $\mathbf{n}$-r-t có lệch với đường giữa gl-ls không và đoạn r-t dựa theo hình dáng tháp mũi có cong không?

- Dựa trên ảnh tư thế mặt nghiêng: Xác định đường nối gốc - chóp mũi (đoạn n-t). Nếu đường viền sống mũi Iõm xuống dưới đường nối này ghi nhận sống mũi Iõm, nếu nằm trên đoạn này là sống mũi gồ. Các trường hợp còn lại tính là sống mũi thẳng.

Hình 1. Tư thế chụp hinh đối tượng nghiên cứu

III. KẾT QUẢ NGHIÊN CỨU

Đặc điểm hình thái mũi ngoài

Bảng 2. Tân suất các loại hình dạng tháp mữi

\begin{tabular}{|c|c|c|c|}
\hline \multirow[b]{2}{*}{ Loại vẹo tháp mũi } & \multicolumn{2}{|c|}{ Giới } & Tống \\
\hline & $\begin{array}{c}\text { Nam } \\
n=129\end{array}$ & $\begin{array}{c}\text { Nữ } \\
n=121\end{array}$ & $\mathbf{n}=\mathbf{2 5 0}$ \\
\hline Không vẹo & $91(70,5)$ & $111(91,2)$ & $202(80,8)$ \\
\hline Loai I: Tháp mũi xương và tháp mũi sun veo nhưng ngược hướng & $5(3,9)$ & $1(0,8)$ & $6(2,4)$ \\
\hline Loại II: Tháp mũi xương vẹo và tháp mũi sụn vẹo cong. & $3(2,3)$ & $1(0,8)$ & $4(1,6)$ \\
\hline Loại III: Tháp mũi xương thẳng và tháp mũi sụn vẹo thẳng. & $9(7,0)$ & $4(3,3)$ & $13(5,2)$ \\
\hline Loai IV: Tháp mũi xương thẳng và tháp mũi sun veo cong. & $8(6,2)$ & $3(2,5)$ & $11(4,4)$ \\
\hline Loại V: Tháp mũi xương và tháp mũi sụn vẹo về cùng một phía. & $13(10,1)$ & $1(0,8)$ & $14(5,6)$ \\
\hline
\end{tabular}

Nhận xét: Chúng tôi ghi nhận có 48 trường hợp vẹo tháp mũi, chiếm 19,2\% ở nhóm nghiên cứu. Trong các loai veo tháp mũi, veo loai $\mathrm{V}$ chiếm tỷ lệ cao nhất $(5,6 \%)$, tần xuất ít nhất là vẹo loại II $(1,6 \%)$. Qua bảng chúng tối thấy sự khác biệt về tần suất các dị dạng tháp mũi và giới là khác nhau có ý nghĩa thống kê.

Bảng 2. Tân suất các dạng sống mưi

\begin{tabular}{|c|c|c|c|}
\hline \multirow{2}{*}{$\begin{array}{c}\text { Dạng } \\
\text { sống mũi }\end{array}$} & \multicolumn{2}{|c|}{ Giới } & \\
\cline { 2 - 4 } & $\mathrm{Nam}=129$ & $\begin{array}{c}\text { Nữ } \\
\mathrm{n}=121\end{array}$ & $\begin{array}{c}\text { Tổng } \\
\mathrm{n}=250\end{array}$ \\
\hline Thắng(\%) & $57(44,2)$ & $51(42,1)$ & $108(43,2)$ \\
\hline Lõm(\%) & $36(27,9)$ & $68(56,2)$ & $104(41,6)$ \\
\hline Gồ$(\%)$ & $36(27,9)$ & $2(1,7)$ & $38(15,2)$ \\
\hline \multicolumn{2}{|l}{} \\
$\chi^{2}=40,386,0<0,001$
\end{tabular}

Nhận xét: Tỷ lệ sông mũi thẳng chiếm nhiều nhất: $43,2 \%$. Sống mũi gồ chiếm số lượng ít nhất với $15,2 \%$. Qua bảng chúng tôi thẩy tần suất các dạng sống mũi có sự khác biệt giữa nam và nữ, sự khác biệt này có ý nghĩa thống kê. Ở nam tỳ lệ sống mũi thẳng chiếm đa số trong khi ở nữ tỷ lệ sống mũi lõm là cao nhất.

\section{BÀN LUÂ̂N}

4.1. Đặc điểm hình dạng tháp mũi: Nghiên cứu bất thường tháp mũi trên 250 bệnh nhân, kết quả ghi nhận 48 trường hợp vẹo tháp mũi, chiếm tỷ lệ 19,2\%. Qua kết quả nghiên cứu cho thấy veo tháp mũi loai I là $2,4 \%$, loai II $1,6 \%$, loại III 5,2\%, loại IV 4,4\%, loại V 5,6\%.

Nghiên cứu của Jong Sook Yi và Yong Ju Jang [9] thực hiện năm 2015 về đặc điểm khuôn mặt ở bệnh nhẩn vẹo mũi ngoài ghi nhận tỷ lệ vẹo tháp mũi xương và tháp mũi sụn (loại $V$ ) chiếm tỷ lệ cao nhất 53/152 trường hợp (34,9\%). Gần tương tự với tỷ lệ vẹo tháp mũi loại $V$ của chúng tôi $14 / 48$ trường hợp $(29,2 \%)$. Kết quả này khác biệt so với nghiên cứu của Ansu Sam [7] và Yong Ju Jang là loại I chiếm tỷ lệ cao nhất, lần lượt là $26 \%$ và $32 \%$.

Chúng tôi thấy có sự khác biệt có ý nghĩa thống kê giữa tần suất vẹo tháp mũi ở mỗi giới $(p<0,05)$. Ở nam veo tháp mũi loại $V$ chiếm ưu thế với $(10,1 \%)$, xếp theo sau là vẹo tháp mũi loại III $(7,0 \%)$, loại IV $(6,2 \%)$, loại I $(3,9 \%)$ và loại II $(2,3 \%)$. Ở nữ thì nhiêu nhất là loại III và IV (3,3\% và $2,5 \%)$. Từ kết quả này chúng tôi nhận thấy ở nam giới chủ yếu là vẹo tháp mũi sụn và tháp mũi xương cùng 1 hướng, ở nữ giới thì thường gặp vẹo phần tháp mũi sụn đơn thuần.

4.2. Đặc điểm hình dạng sống mũi. Chúng tôi thấy hình dạng sống mũi chủ yếu là thẳng $(43,2 \%)$ và lõm $(41,6 \%)$. Sống mũi gồ chiếm tỷ lệ thấp nhất là $15,2 \%$. Kết quả này tương tự với nghiên cứu của Trần Thị Anh Tú [2] và Nguyễn Thành Nhân [1]. 
Kết quả tần suất các dạng sống mũi ở hai giới nam và nữ được thể hiện sự khác biệt giữa các nhóm này là có ý nghĩa thống kê $(p<0,05)$. Cụ thể sống mũi lõm ở nữ giới chiếm đa số $(56,2 \%)$, trong khi ở nam giới đa phần là sống mũi thằng $(44,2 \%)$. Trong đó, sống mũi gồ thì ưu thế vượt trội ở số lượng bệnh nhân nam (36 trường hợp) so với nữ (2 trường hợp).

Tóm lại khi khảo sát đường viền sống mũi so với đường nối gốc - chóp mũi trên ảnh mặt nghiêng, chúng tôi nhận thấy sống mũi thẳng chiếm 43,2\%, sống mũi lõm 41,6\%, sống mũi gồ $15,2 \%$. Nam giới sống mũi thường thẳng $(44,2 \%)$, nữ giới hay gặp sống mũi lõm (56,2\%). Sống mũi gồ hay gặp ở nam giới $(27,9)$ hơn là ở nữ giới $(1,7 \%)$.

4.3. Mối liên hệ giữa vẹo vách ngăn và hình dạng mũi ngoài. Kết quả cho thấy có sự khác biệt về tần suất các loại vẹo vách ngăn ở các dị hình tháp mũi loại I, III, V có ý nghĩa thống kê $(p<0,05)$. Từ đó, chúng tôi rút ra kết luận vẹo vách ngăn và hình dạng mũi ngoài có liên quan với nhau. Nhận định của chúng tôi tương tự với kết quả công trình nghiên cứu của Ansu Sam [7].

Khi nghiên cứu trên 260 trường hợp phẫu thuật chỉnh hình mũi ngoài, Foda [4] tiến hành chia hình dạng mũi ngoài thành 3 dạng: vẹo tháp mũi xương đơn thuần, vẹo tháp mũi sụn đơn thuần, và vẹo mũi ngoài kết hợp vẹo tháp mũi sụn và tháp mũi xương. Foda nhận thãy các trường hợp vẹo tháp mũi phần sụn đều bao gồm vẹo vách ngăn kèm theo.

Chúng tôi ghi nhận ở vẹo tháp mũi loại I: tháp mũi xương và tháp mũi sụn đều vẹo nhưng ngược hướng, chiếm tỷ lệ cao nhất là vẹo vách ngăn loại 4 là $66,7 \%$. Điều này có thể được giải thích là do veo vách ngăn loại 4 theo Mladina định nghĩa thì giống như dạng vẹo vách ngăn hình chữ " $S$ ", trong đó vẹo phần sụn vách ngăn ở phía trước và vẹo phần xương vách ngăn ở phía sau. Vì hai phần này vẹo 2 bên khác nhau cho nên phần sụn vách ngăn sẽ kéo phần tháp mũi sụn, phần xương vách ngăn sẽ kéo tháp mũi xương theo hai hướng ngược nhau.

ở nhóm vẹo tháp mũi loại III (tháp mũi xương thẳng, tháp mũi sụn vẹo thẳng), chiếm ưu thế là vẹo vách ngăn loại $7(38,5 \%)$ và loại 2 $(30,8 \%)$. Theo phân loại của Mladina, vẹo vách ngăn loại 7 là sự phối hợp của các dạng vẹo vách ngằn nên bao gồm vẹo vách ngăn loại 2 . Và ở nhóm vẹo tháp mũi loại $V$ (tháp mũi xương và tháp mũi sụn vẹo cùng hướng), vẹo vách ngăn loại 2 chiếm một nửa, vẹo vách ngăn loại
3, 4, 6 chiếm tỷ lệ bằng nhau (14,3\%).

Điều này đã được áp dụng vào các phẫu thuật chỉnh hình mũi ngoài vẹo. Tác giả Foda [4] nghiên cứu trên 260 đối tượng chỉnh hình mũi vẹo, ghi nhận có đến 232 (89\%) trường hợp có kết hợp chỉnh hình vách ngăn. Và kết quả theo dõi sau phẫu thật tỷ lệ thành công được đánh giá trên 2 tiêu chí: hết nghẹt mũi và mũi ngoài thẳng đạt $80 \%$. Foda qua đó đề nghị trước khi tiến hành phẫu thuật trên bệnh nhân bị vẹo mũi ngoài thì phải đánh giá và khám kỹ các bất thường vách ngăn để tiến hành can thiệp lúc mổ.

Tác giả Arima [3] tiến hành theo dõi các trường hợp chỉnh hình vẹo mũi ngoài, bao gồm vẹo tháp mũi xương và tháp mũi sụn ghi nhân tỷ lệ có kết hợp chỉnh hình vách ngăn là $90 \%$. Tác giả giải thích rằng các trường hợp trong nhóm nghiên cứu đều có kết hợp vẹo vách ngăn kèm theo. Sau phẫu thuật chỉnh hình mũi ngoài, bên cạnh sự co kéo của cơ vùng mũi và hệ thống dây chằng vùng mũi ngoài, vách ngăn vẹo là yếu tố làm cho tháp mũi ngoài trở lại hình dạng vẹo như cũ. Khi nhận ra tác động của vẹo vách ngẳn đối với dị dạng mũi ngoài trong nghiên cứu của mình, Arima đề xuất nên chỉnh hình vách ngăn vẹo dù bệnh nhân có triệu chứng nghẹt mũi do vách ngăn gây ra hay khồng.

Tóm lại, chúng tôi nhận thây vẹo vách ngăn theo phân loại Mladina [6] và hình dạng tháp mũi theo Yong Ju Jang là có liên quan với nhau. Vẹo vách ngắn loại 2 (vẹo phần van mũi có chạm đến góc van mũi trong) hay gặp ở vẹo tháp mũi xương và tháp mũi sụn cùng hướng. Vẹo vách ngăn loại 4 (vách ngăn hình chữ " $S$ ") hay gặp ở tháp mũi xương vẹo kết hợp với vẹo thẳng tháp mũi sụn nhưng ngược hướng. Vẹo vách ngăn loại 7 (vẹo phức tạp) hay gặp ở vẹo tháp mũi sụn đơn thuần.

\section{KẾT LUÂN}

Vẹo mũi ngoài có mối liên quan với vẹo vách ngăn đặc biệt, vẹo vách ngăn loại 2 (vẹo phần van mũi có chạm đến góc van mũi trong) hay gặp ở vẹo tháp mũi xương và tháp mũi sụn cùng hướng. Vẹo vách ngăn loại 4 (vách ngằn hình chữ " $S$ ") hay gặp ở tháp mũi xương vẹo kết hợp với vẹo tháp mũi sụn nhưng ngược hướng. Vẹo vách ngăn loại 7 (vẹo phức tạp) hay gặp ở vẹo tháp mũi sụn đơn thuần.

\section{TÀI LIÊU THAM KHẢO}

1. Nguyễn Thành Nhân (2016), "Nghiên cứu tạo hình nâng mũi bằng mô tự thân phối hợp với vật liệu nhân tạo", Luận án tiển sĩ Y học, Viện Nghiển cứu khoa học Y Dược Lâm Sàng 108. 
2. Trân Thị Anh Tú (2003), "Hình thái, cấu trúc tháp mũi người trưởng thành", Luận án tiến sĩ $Y$ hoc, Trường ĐHYD TP. Hồ Chí Minh.

3. Arima L. M. et al. (2011), "Crooked nose: outcome evaluations in rhinoplasty", Brazilian journal of otorhinolaryngology. 77 (4), pp. 510-515.

4. Foda H. M. (2005), "The role of septal surgery in management of the deviated nose", Plastic and Reconstructive Surgery. 115 (2), pp. 406-415.

5. Godley F. A. (1997), "Nasal septal anatomy and its importance in septal reconstruction", Ear, nose \& throat journal. 76 (8), pp. 498-506.

6. Mladina $\mathbf{R}$. et al. (2008), "Nasal septal deformities in ear, nose, and throat patients: an international study", American journal of otolaryngology. 29 (2), pp. 75-82.

7. Sam A. et al. (2012), "Nasal septal deviation and external nasal deformity: a correlative study of 100 cases", Indian Journal of Otolaryngology and Head \& Neck Surgery. 64 (4), pp. 312-318.

8. Stepnick D, Guyuron B (2010), "Surgical treatment of the crooked nose", Clinics in Plastic Surgery. 37 (2), pp. 313-325.

9. Yi J. S. et al. (2015), "Frequency and characteristics of facial asymmetry in patients with deviated noses", JAMA facial plastic surgery. 17 (4), pp. 265-269.

\title{
ĐĂC ĐIỂM LÂM SÀNG VÀ MộT SỐ YẾU Tố LIÊN QUAN CỦA BỆNH GIANG MAI TẠI BỆNH VIÊ̂N DA LIỄU TRUNG ƯO'NG
}

\author{
Trần Cẩm Vân*, Hoàng Thị Ái Liên*, Phạm Thị Minh Phương*
}

\section{TÓM TẮT}

Muc tiêu: Mô tả đặc điểm lâm sàng và một số yễu tổ liên quan của bệnh giang mai tại Bệnh viện $\mathrm{Da}$ liếu Trung ương từ tháng 4/2019 -6/2020. Đối tướng và phương pháp: Mô tả cắt ngang trên 339 bệnh nhân được chẩn đoán xác định bênh giang mai mới và chưa điều trị đến khám trong thời gian nghiên cứu. Kết quả: Tỉ lệ bệnh nhân giang mai trong các bệnh lây truyền qua đường tình dục là 9,33\%; trong đó $87 \%$ nhiếm giang mai đơn thuần, $5 \%$ có kết hợp với nhiễm HIV. Thể lâm sàng chủ yếu là giang mai kín muôn $44,8 \%$, tiếp theo giang mai 2 với $35,4 \%$, có $4,1 \%$ giang mai bẩm sinh. Chủ yếu nhóm tuổi 21-30 với $51,3 \%$, nam gặp nhiều hơn nữ $(79,7 \%$ so với $20,3 \%$ ), chưa có gia đình $66,1 \%$. Yếu tố nguy cơ quan hề tình dục không an toàn $75,5 \%$, quan hệ đồng giới $55,2 \%$. Đặc điểm lâm sàng chủ yếu của giang mai 1 là săng $(68,1 \%)$, giang mai 2 là sẩn $(74,6 \%)$. Kết luận: Bệnh giang mai là một vấn đề cần được xã hội quan tâm, đặc biệt với nhóm đối tượng nam giới trưởng thành, chưa có gia đình, có quan hệ đồng giới.

Từ khóa: Giang mai

\section{SUMMARY}

\section{CLINICAL CHARACTERISTICS OF PATIENT WITH SYPHILIS AND RELATED FACTORS} AT NATIONAL HOSPITAL OF

DERMATOLOGY AND VENEREOLOGY

Objectives: To investigate clinical characteristics and related factors of genital mycoplasma at National hospital of Dermatology and Venereology from 4/2019 to 6/2020. Population and methods: Crosssectional description of three hundred and thirdty-nine

*Bênh viên Da liễu Trung Ương.

Chịu trách nhiệm chính: Trân Cẩm Vân

Email: trancamvan.dl@gmail.com

Ngày nhận bài: 11.3.2021

Ngày phản biên khoa hoc: 13.5.2021

Ngày duyệt bài: 19.5.2021 patients with syphilis and no treatment before going to hospial. Results: The rate of patients with syphilis in sexually transmitted diseases was $9.33 \%$; of which $87 \%$ were syphilis alone, $5 \%$ co-infection with HIV. The main clinical stage was late syphilis $44.8 \%$, following syphilis stage of 2 with $35.4 \%$, congenital syphilis $4.1 \%$. Maily the age group $21-30$ with $51.3 \%$ men higher than women $(79.7 \%$ and $20.3 \%)$ unmarried $66.1 \%$. The risk factor for unprotected sex was $75.5 \%$, same-sex sexual activity $55.2 \%$. The main clinical feature of syphilis stage of 1 was chancres $68.1 \%$; stage of 2 was papuloma $74.6 \%$. Conclusion: Syphilis is an issue that needs to be of social concern, especially for group of men, unmarried and same-sex sexual activity.

Key words: syphilis

\section{I. Đă̆T VẤN ĐỀ}

Giang mai (Syphilis) là một bệnh nhiễm trùng kinh diễn do Treponema pallidum gây nên. Tứ thế kỷ XX, sau khi các nhà khoa học Đức mô tả xoắn khuẩn này, giang mai trở thành một bệnh dịch hiện đại, gây ảnh hưởng tới hàng triệu người trên thế giới [1]. Biểu hiện lâm sàng của bệnh đa dạng, dễ nhầm với các bệnh ngoài da khác, một số trường hợp sẩn giang mai phì đại ở hậu môn đã có chẩn đoán nhầm với sùi mào gà. Đặc biệt bệnh đã được chứng minh là góp phần làm tăng nguy cơ mắc và lây nhiễm HIV. Tổ chức $Y$ tế Thế giới (WHO) ước tính 17,7 triệu người trên toàn câuu từ 15-49 tuổi mắc bệnh, với khoảng 5,6 triệu người mắc mới mỗi năm [2]. Theo O’Byrne và cộng sự (2019), với khả năng lây nhiễm lên đến 10-30\% sau mỗi lần quan hệ tình dục, tỉ lệ bệnh đã tăng lên 300\% từ năm 2000 ở một số quốc gia Phương Tây [3]. Trong đó, bệnh có xu hướng gặp ở độ tuổi trẻ 25-34 tuổi, có nhiều bạn tình, $40 \%$ là đồng nhiễm với 